\title{
Comparison of shared decision making in patients undergoing hemodialysis and peritoneal dialysis for choosing a dialysis modality
}

\author{
Sepide Ghodsian ${ }^{1}$, Mansour Ghafourifard ${ }^{1,2^{*}}$ and Akram Ghahramanian ${ }^{1}$
}

\begin{abstract}
Background: Shared decision making (SDM) is recognized as the gold standard for patient-centered care. This study aimed to assess and compare the SDM among patients undergoing hemodialysis and peritoneal dialysis for choosing a dialysis modality.

Methods: This is a cross-sectional study that was performed on 300 dialysis patients (218 HD and 82 PD) referred to two Dialysis Centers. Data were collected using demographic information and a 9-item Shared Decision Making Questionnaire (SDM-Q-9). The data were analyzed using ANOVA and independent t-test by SPSS software.

Results: The mean SDM-Q-9 score in all samples (PD and HD) was $21.94 \pm 15.08$ (in a possible range of 0 to 45). Results of the independent t-test showed that the mean SDM-Q-9 score in PD patients (33.11 \pm 10.08$)$ was higher than HD patients $(17.14 \pm 74.24)(p<0.001)$. The results showed a statistically significant difference in mean SDM-Q9 score based on patients' age, educational level, and income $(p<0.05)$.

Conclusion: Implementing shared decision making and providing information on RRT should be started in the early stage of CKD. The health care providers should involve patients with CKD and their families in dialysis-related decisions and it should be started in the early stage of CKD.
\end{abstract}

Keywords: Shared decision making, Hemodialysis, Peritoneal dialysis, Nursing care

\section{Introduction}

Chronic kidney disease (CKD) is a disease with multiple causes that leads to an irreversible decrease in kidney functions and often leads to end stage kidney disease (ESKD) $[1,2]$. Considering the increase in the elderly population and the increase in underlying diseases such as diabetes mellitus, hypertension, and obesity [3, 4], the global prevalence of CKD is also increasing $8 \%$ annually

\footnotetext{
* Correspondence: m.ghafori@yahoo.com

'Department of Medical Surgical Nursing, Faculty of Nursing and Midwifery, Tabriz University of Medical Sciences, Tabriz, Iran

${ }^{2}$ Medical Education Research Center, Health Management and Safety Promotion Research Institute, Tabriz University of Medical Sciences, Tabriz, Iran
}

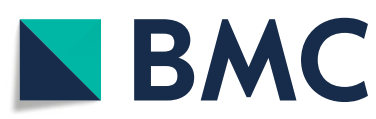

( ) The Author(s). 2021 Open Access This article is licensed under a Creative Commons Attribution 4.0 International License, which permits use, sharing, adaptation, distribution and reproduction in any medium or format, as long as you give appropriate credit to the original author(s) and the source, provide a link to the Creative Commons licence, and indicate if changes were made. The images or other third party material in this article are included in the article's Creative Commons licence, unless indicated otherwise in a credit line to the material. If material is not included in the article's Creative Commons licence and your intended use is not permitted by statutory regulation or exceeds the permitted use, you will need to obtain permission directly from the copyright holder. To view a copy of this licence, visit http://creativecommons.org/licenses/by/4.0/. The Creative Commons Public Domain Dedication waiver (http://creativecommons.org/publicdomain/zero/1.0/) applies to the data made available in this article, unless otherwise stated in a credit line to the data.

[5]; however, the growth of this disease in Iran is reported to be $12 \%$ [6]. It is estimated that the number of patients with ESKD will increase from 2.6 million in 2010 to 5.4 million in 2030 worldwide [7]. The prevalence of CKD in different countries varies by ethnic origin and social class and the risk of the disease in countries with lower socioeconomic status is $60 \%$ higher than in developed countries [5]. Control and treatment of this disease impose a high cost and a huge economic burden on the health care system, patients, and their families [8]. A recent study on the global burden of chronic kidney disease showed that treatment costs for CKD and costs related to the application of life-saving 
renal replacement techniques have raised during recent years [9].

Patients with ESKD need to choose one of the renal replacement therapies (RRT) choices including kidney transplantation or dialysis (hemodialysis or peritoneal dialysis), to survive and prevent uremia and other complications [10-12]. Among these treatments, hemodialysis is the most common treatment in Iran and the world [10,13, 14]; about $87 \%$ of patients with ESKD undergo hemodialysis (HD) and only $13 \%$ of them are on peritoneal dialysis (PD) worldwide [13]. According to the latest statistics, there are $95 \%$ of HD patients and only 5\% PD patients in Iran [15]. Choosing the type of RRT based on the patient's conditions is considered a challenge for CKD patients [8]. Although kidney transplantation is the best choice for this disease, it cannot be performed for all patients due to the lack of easy access to donated kidneys, lack of information about transplanted kidneys, and taking into account the patient's conditions [16]. Therefore, most patients with CKD should choose between home peritoneal dialysis (PD), in-center hemodialysis (IC-HD), and home hemodialysis (Home-HD. However, home HD is not usually offered and their choices are limited to in-center HD or home PD $[17,18]$.

Choosing the best treatment for patients requires cooperation between the patient and the healthcare team, which is called shared decision making (SDM) [19]. SDM is recognized as the gold standard for patient-centered care [20] and this approach has been proposed in more diseases, especially in chronic diseases [21]. SDM is a collaborative process in which patients, caregivers, family members, and even friends of the patient involve in health care decisions for patients, and the final decision is made based on the patient's values, preferences, and conditions by taking into account the advantages and disadvantages of each treatment $[19,22]$. The first step in this approach is to encourage the patient to engage in shared decision making, and this happens when sufficient information about each of the treatment options is made available to the patients and their family where the health care providers try to avoid imposing their opinions on patients choice [18].

Nurses have the most direct contact time with patients and they could influence patients' knowledge and perception on shared decision making process [23]. Nephrology nurses could influence patients' decisions by providing educations on modality selection. They can guide patients and their families for choosing the dialysis modality [24]. Providing education by nurses as a health care team could help patients to better understand chronic kidney diseases, weigh available renal replacement therapies, and decide on the modality selection
[25]. During the shared decision process, nurses share the professional knowledge with the patients, and in turn, patients share their personal knowledge on their own daily life and health care. Finally, they discuss the choices and decide which dialysis modality (PD or HD) is best for him or her [26].

For providing a high quality care in patients with CKD, SDM approach has been suggested to choose the RRTs. For this, the healthcare teams need to explain all modalities to the patients and the advantages and disadvantages of each modality [27]. According to the literature review, many patients who have recently been diagnosed with ESKD do not have sufficient knowledge and information about RRT choices and are treated by one of RRT without even knowing its side effects [16]. Furthermore, previous studies show that many patients are not prepared enough to start dialysis [28] and they do not play an active role in choosing the type of dialysis $[29,30]$.

According to the literature review, SDM and patient involvement in treatment decisions are not still included in the national health system in Iran and it needs to be incorporated in clinical settings [31]. Home hemodialysis is not mainley offered in Iran and patients need to select the incenter hemodialysis or peritoneal dialysis. In terms of dialysis choice in Iran, the nephrologists generally decide the dialysis choice for patients and they usually suggest the incenter hemodialysis. However, some nephrologists may suggest the PD for patients or their family and there are no specific guidelines or decision aids for SDM in patients with CKD. Furthermore, there are no specific programs in hemodialysis units (including these two dialysis centers of our study) for predialysis education for the choice of dialysis. In some cases, nurses may suggest the PD modality for patients, but finally, the nephrologist decides the choice of dialysis modality. Moreover, many patients with emergency situations start renal replacement therapy with hemodialysis and continue on HD forever. There are notably more than $30,000 \mathrm{HD}$ patients and only $1600 \mathrm{PD}$ patients in Iran.

Although many patients can start and continue PD, most of patients with ESKD undergo hemodialysis [32, 33]. In this regard, a study by Erlang et al. [34] showed that PD was not introduced as one of RRTs for about $88 \%$ of dialysis patients. A literature review shows that PD leads to minimal disruption or change in the patient's daily life and strengthens the patient's self-care and independence [35]. PD is also considered as the best type of dialysis for patients who are on the waiting list for a kidney transplant [36]. In addition, PD is recommended in diabetic patients and patients with chronic heart failure, and this type of dialysis reduces the mortality rate of these patients $[37,38]$. Other advantages of PD include the lower cost of this modality 
than other RRTs [39] and it is more cost-effective than HD [32]. Furthermore, previous studies revealed that PD leads to greater patient satisfaction [35, 40], as well as higher quality of life compared to HD [41]. However, PD has some limitations. This dialysis should be carried out every day and patients with PD has a greater risk of developing peritonitis, abdominal hernia, and disturbed body image. Furthermore, it is difficult to perform this type of dialysis in patients who have severe neurological problems and where there is no one to take care of patients with physical impairment or poor vision [42].

In order to involve patients in SDM regarding the type of dialysis treatment, patients and their caregivers should have a comprehensive understanding of the differences of dialysis methods and the impact of dialysis on their daily lives [43]. Patients who play an active role in SDM not only pay more attention to recommendations made by physicians and medical staff [44] but also have high self-confidence [45]. Moreover, SDM increases patient preparedness to overcoming the challenges of treatment-related problems and complications and reduces their worries [45]. Other advantages of the SDM approach include positive outcomes such as increasing the patient's quality of life and maintaining patients' independence [46]. However, when the patient is not involved in clinical decision-making and the choice of treatment is not selected based on the individual's preferences and values, it may lead to conflict in decisionmaking [47] and may result in unpleasant consequences such as decreased patient's motivation needed for treatment adherence, feeling of regret and guilt, and even blaming of the medical staff by the patient [27].

Although there have been studies on the effect of SDM in some diseases, a literature review shows that there are few studies on the field of dialysis [48]. Since $\mathrm{SDM}$ is an important factor in care of dialysis patients, we decided to assess and compare the SDM among patients undergoing hemodialysis and peritoneal dialysis for choosing the dialysis modality.

\section{Methods}

\section{Design}

This cross-sectional study was performed on 300 dialysis patients (218 HD and $82 \mathrm{PD}$ ) referred to two Dialysis Centers (Imam Reza and Sina Hospitals) affiliated to Tabriz University of Medical Sciences, Tabriz. All methods were performed in accordance with the relevant guidelines for cross-sectional studies (STROBE Statement).

\section{Sample and setting}

There were 400 patients with HD and 90 patients with PD in these two dialysis centers. We used Krejcie \&
Morgan's sampling table to determine the sample size of the study [29]. The patients were selected using a convenience sampling method. Inclusion criteria included patients aged over 18 years and who were undergoing hemodialysis or peritoneal dialysis. We included patients who were conscious and alert. We did not include the confused patients or those with cognitive problems based on the patient's medical records.

\section{Data collection}

Data were collected using demographic information and a 9item Shared Decision Making Questionnaire (SDM-Q-9) from January to April 2020. SDM-Q was developed by Robinski et al. [43] in 2015 to probe the SDM process. The questionnaire consists of 9 questions that are answered based on a 6-point Likert scale (ranging from strongly disagree $=0$, to strongly agree $=5$ ). The possible score range is $0-45$, with a higher score indicating a high SDM level. The overall score of SDM-Q-9 was standardized to 0-100.

The validity and reliability of this instrument have been investigated in previous studies with a Cronbach's alpha of $\alpha=94 \%$, which indicates the high reliability of the scale [43]. In this study, the validity of the Persian version of the SDM-Q-9 was investigated by the content validity method. For this purpose, after being translated and re-translated by an English language expert, the questionnaire was given to ten faculty members of the faculty of Nursing and Midwifery and the questionnaire was revised based on their comments. Cronbach's alpha of the Persian version of SDM-Q-9 was $98 \%$.

The questionnaire was administered to the patient to complete it by self-administration method. However, a research coordinator was trained to interview patients who were unable to self-administer the SDM-Q-9 questionnaire, such as illiterate patients and patients with poor vision or physical impairment. She completed the questionnaire based on the participants' responses. In addition, informations on patients' clinical characteristics such as the cause of renal failure, duration of dialysis, and CKD comorbidities were also recorded.

\section{Data analysis}

The collected data were analyzed using ANOVA and independent t-test by SPSS (ver. 21) software. The data were presented in tables with using descriptive analysis such as mean and standard deviation. The significance level was set at $p<0.05$.

\section{Results}

Background characteristics of the patients

According to the result, the mean age of the subjects was $54.84 \pm 14.98$ years. A total of 168 patients were 
male and 132 were female. The majority of participants (84\%) are married. The mean duration of hemodialysis treatment was $28.96 \pm 24.86$ months and the mean duration of peritoneal dialysis treatment was $38.68 \pm 26.07$ months (Table 1). Concerning CKD etiology, the most common cause was hypertension (24.6\%), diabetes mellitus (18.7\%), and a combination of diabetes mellitus and hypertension (17\%).

\section{Patients' perception of shared decision making}

Overall, the mean SDM-Q-9 score in all samples (PD and HD) was $21.94 \pm 15.08$ (in a possible range of 0 to 45). Results of the independent t-test showed that the mean SDM-Q-9 score in PD patients (33.11 \pm 10.08) was higher than HD patients $(17.14 \pm 74.24)$, which was statistically significant $(p<0.001)$. Also, PD patients showed a higher score in all items of the SDM-Q-9 $(p<0.05)$.
Details of participants' responses to each item of the SDM-Q-9 are shown in Table 2. According to the results of the questionnaire, the highest mean score $(2.1 \pm$ 46.77) among HD patients was related to item 1, "My physician told me that there are different methods of dialysis (HD and PD) to treat my disease" and the lowest mean score $(1.80 \pm 1.64)$ was related to Item 7 , "My physician and I examined the types of dialysis (hemodialysis and peritoneal dialysis) ". In the case of PD patients, the highest mean score $(3.42 \pm 1.92)$ was related to Item 9" My physician and I agreed to continue treatment" and the lowest mean score $(3.37 \pm 1.50)$ was related to Item 5 "My physician helped me understand all the information about HD and PD".

\section{Comparison of SDM based on patients' demographic}

The results of the present study showed no statistically significant difference in mean SDM-Q-9 score based on

Table 1 Demographic characteristics of patients $(N=300)$

\begin{tabular}{|c|c|c|c|}
\hline \multirow[t]{2}{*}{ Variables } & $\begin{array}{l}\mathrm{HD} \\
N=218\end{array}$ & $\begin{array}{l}\mathrm{PD} \\
N=82\end{array}$ & $\begin{array}{l}\text { TOTAL } \\
N=300\end{array}$ \\
\hline & Mean \pm SD & Mean \pm SD & Mean \pm SD \\
\hline Age (years) & $56.44 \pm 14.10$ & $58.58 \pm 15.46$ & $54.84 \pm 14.98$ \\
\hline \multirow[t]{2}{*}{ Duration of dialysis treatment (month) } & $28.96 \pm 24.86$ & $38.68 \pm 26.07$ & $31.62 \pm 25.52$ \\
\hline & $N(\%)$ & $N(\%)$ & $N(\%)$ \\
\hline \multicolumn{4}{|l|}{ Gender } \\
\hline Male & $132(60.6 \%)$ & $36(43.9 \%)$ & $168(56 \%)$ \\
\hline Female & $86(39.4 \%)$ & $46(56.1 \%)$ & $132(44 \%)$ \\
\hline \multicolumn{4}{|l|}{ Marital status } \\
\hline Single & $12(5.5 \%)$ & $16(19.5 \%)$ & $28(9.3 \%)$ \\
\hline Married & $191(87.6 \%)$ & $61(74.4 \%)$ & $252(84 \%)$ \\
\hline Divorced & $0(0 \%)$ & $1(1.2 \%)$ & $1(0.4 \%)$ \\
\hline Widow & $15(6.9 \%)$ & $4(4.9 \%)$ & $19(6.3 \%)$ \\
\hline \multicolumn{4}{|l|}{ Education level } \\
\hline Illiterate & $55(25.2 \%)$ & $17(20.7 \%)$ & $72(24 \%)$ \\
\hline Elementary school & $57(26.2 \%)$ & $16(19.5 \%)$ & $73(24.3 \%)$ \\
\hline Junior High school & $55(25.2 \%)$ & $19(23.2 \%)$ & $74(24.7 \%)$ \\
\hline Diploma & $36(16.5 \%)$ & $12(14.6 \%)$ & $48(16 \%)$ \\
\hline University & $15(6.9 \%)$ & $18(22 \%)$ & $33(11 \%)$ \\
\hline \multicolumn{4}{|l|}{ Living in } \\
\hline Urban & $195(89.4 \%)$ & $66(80.5 \%)$ & $261(87 \%)$ \\
\hline Rural & $23(10.6 \%)$ & $16(19.5 \%)$ & $39(13 \%)$ \\
\hline \multicolumn{4}{|l|}{ Income } \\
\hline$<50$ US dollars & $114(52.3)$ & $20(24.4)$ & $134(44.7)$ \\
\hline 50-100 US dollars & $71(32.6)$ & $21(25.6)$ & $92(30.7)$ \\
\hline 100-150 US dollars & $25(11.5)$ & $35(42.7)$ & $60(20)$ \\
\hline$>150$ US dollars & $8(3.7)$ & $6(7.3)$ & $14(4.6)$ \\
\hline
\end{tabular}


Table 2 Item characteristics for the SDM-Q-9

\begin{tabular}{|c|c|c|c|c|}
\hline $\begin{array}{l}\text { Items } \\
\text { (score for each item ranged } 0 \text { to } 5 \text { ) }\end{array}$ & $\begin{array}{l}\text { HD } \\
\text { mean } \pm s d\end{array}$ & $\begin{array}{l}\text { PD } \\
\text { mean } \pm s d\end{array}$ & total & $\begin{array}{l}\text { COMPARISON } \\
\text { OF HD \& PD }\end{array}$ \\
\hline $\begin{array}{l}\text { 1) My Doctor told me that there are different dialysis modalities (hemodialysis and } \\
\text { peritoneal dialysis) for treating my medical condition }\end{array}$ & $2.46 \pm 1.77$ & $3.87 \pm 1.38$ & $2.85 \pm 1.78$ & $\begin{array}{l}T=-6.51 \\
P \text { value }=0.0003\end{array}$ \\
\hline $\begin{array}{l}\text { 2) My Doctor made clear that a decision between hemodialysis and peritoneal } \\
\text { dialysis needs to be made. }\end{array}$ & $2.02 \pm 1.66$ & $3.78 \pm 1.24$ & $2.50 \pm 1.74$ & $\begin{array}{l}T=-8.65 \\
P \text { value }=0.0003\end{array}$ \\
\hline $\begin{array}{l}\text { 3) My Doctor wanted to know exactly how I Want to be involved in making the } \\
\text { decision between hemodialysis and peritoneal dialysis }\end{array}$ & $1.91 \pm 1.63$ & $3.53 \pm 1.25$ & $2.35 \pm 1.69$ & $\begin{array}{l}T=-8.14 \\
P \text { value }=0.0001\end{array}$ \\
\hline $\begin{array}{l}\text { 4) My Doctor precisely explained the advantages and disadvantages of hemodialysis } \\
\text { and peritoneal dialysis }\end{array}$ & $1.87 \pm 1.58$ & $3.59 \pm 1.39$ & $2.34 \pm 1.71$ & $\begin{array}{l}\mathrm{T}=-8.66 \\
P \text { value }=0.0002\end{array}$ \\
\hline $\begin{array}{l}\text { 5) My Doctor helped me understand all of the information concerning hemodialysis } \\
\text { and peritoneal dialysis }\end{array}$ & $1.82 \pm 1.60$ & $3.50 \pm 1.37$ & $2.28 \pm 1.71$ & $\begin{array}{l}T=-8.36 \\
P \text { value }=0.0002\end{array}$ \\
\hline $\begin{array}{l}\text { 6) My Doctor asked me which dialysis treatment option (hemodialysis Or peritoneal } \\
\text { dialysis) I prefer }\end{array}$ & $1.89 \pm 1.65$ & $3.59 \pm 1.30$ & $2.36 \pm 1.74$ & $\begin{array}{l}T=-8.35 \\
P \text { value }=0.0002\end{array}$ \\
\hline $\begin{array}{l}\text { 7) My Doctor and I Thoroughly weighed the different dialysis treatment options } \\
\text { (hemodialysis And peritoneal dialysis) }\end{array}$ & $1.80 \pm 1.64$ & $3.58 \pm 1.34$ & $2.29 \pm 1.75$ & $\begin{array}{l}T=-8.75 \\
P \text { value }=0.0001\end{array}$ \\
\hline $\begin{array}{l}\text { 8) My Doctor and I Selected a dialysis treatment option (hemodialysis Or peritoneal } \\
\text { dialysis) together }\end{array}$ & $1.84 \pm 1.66$ & $3.68 \pm 1.34$ & $2.35 \pm 1.77$ & $\begin{array}{l}T=-8.95 \\
P \text { value }=0.0003\end{array}$ \\
\hline 9) My Doctor and I Reached an agreement on how to proceed & $2.09 \pm 1.70$ & $3.92 \pm 1.42$ & $2.59 \pm 1.82$ & $\begin{array}{l}T=-8.68 \\
P \text { value }=0.0002\end{array}$ \\
\hline SDM-Q-9 total score (ranged 0-45) & $17.74 \pm 14.24$ & $33.08 \pm 11.10$ & $21.94 \pm 15.08$ & $\begin{array}{l}T=-8.79 \\
P \text { value }=0.0001\end{array}$ \\
\hline
\end{tabular}

gender, occupation, and living area (Urban or rural) $(P>$ 0.05). However, education level had a significant effect on the mean SDM-Q-9 score $(P<0.05)$. In terms of total SDM-Q-9, Post hoc analysis showed that illiterate patients $(17.14 \pm 73.83)$ had a lower score than people with diploma degree $(26.14 \pm 96.75)$ and university education (26.96 14.75) $(P<0.05)$. Moreover, individuals with elementary education $(18.14 \pm 72.87)$ had a lower score than patients with diploma degree $(26.96 \pm 14.75)$ and university education $(26.96 \pm 14.75)(P<0.05)$ (Table 3$)$.

Concerning income level, the results show that monthly income had a significant effect on the mean SDM-Q-9 score $(P<0.05)$; Post hoc analysis showed that patients with a monthly income of lower than 50 Us dollars $(18.14 \pm 62.19)$ had a lower SDM score compared with patients with a monthly income of 100-150 US dollars $(26.15 \pm 75.31)$ and those with more than 150 Us dollars $(30.85 \pm 12.13)(P<0.05)$. Moreover, there was a statistically significant difference between individuals with a monthly income of $10-20$ million $(22.27 \pm 15.37)$ and those with an income level above 150 US dollars $(30.85 \pm 12.13)(P<0.05)$.

Pearson correlation test showed a significant inverse relationship between age and SDM-Q-9 score, so that with increasing age, SDM score decreases $(p<0.05$, $\mathrm{r}=-0.382)$.

\section{Discussion}

Providing person-centered care has recently been encouraged in the health care systems. Person-centered care is a holistic approach in which a good therapeutic relationship is established between

Table 3 Comparison of mean score of SDM-Q-9 based on patients characteristics $(N=300)$

\begin{tabular}{|c|c|c|c|}
\hline Variables & Mean & SD & $P$-value \\
\hline \multicolumn{4}{|l|}{ Gender } \\
\hline Male & 21.91 & 14.72 & $P=0.976$ \\
\hline Female & 21.96 & 15.58 & $\mathrm{~T}=0.030$ \\
\hline \multicolumn{4}{|l|}{ Marital status } \\
\hline Married & 21.39 & 14.80 & $P=0.000003$ \\
\hline Single & 33.17 & 12.77 & $F=9.97$ \\
\hline Divorced & 45 & 11.51 & \\
\hline Widow & 11.42 & 11.43 & \\
\hline \multicolumn{4}{|l|}{ Education level } \\
\hline Illiterate & 17.73 & 14.83 & $P=0.00002$ \\
\hline Elementary school & 18.72 & 14.87 & $F=7.04$ \\
\hline Junior High school & 21.77 & 15.04 & \\
\hline Diploma & 26.96 & 14.75 & \\
\hline University & 26.96 & 14.75 & \\
\hline \multicolumn{4}{|l|}{ Living in } \\
\hline Urban & 22.47 & 15.22 & $P=0.112$ \\
\hline Rural & 18.35 & 13.74 & $\mathrm{~T}=0.067$ \\
\hline \multicolumn{4}{|l|}{ Income } \\
\hline$<50$ US dollars & 18.62 & 14.19 & $F=6.13$ \\
\hline 50-100 US dollars & 22.27 & 15.37 & $P=0.00004$ \\
\hline 100-150 US dollars & 26.75 & 15.31 & \\
\hline$>150$ US dollars & 30.85 & 12.13 & \\
\hline
\end{tabular}


patients and healthcare providers [49]. With regard to the nature of person-centered care, patient care decisions are made based on the needs, preference, and performance of the patients and they are involved in their treatment decisions. In fact, the patient plays an active role in the treatment process [50]. SDM is at the highest level of person-centered care and provide an opportunity for patients to engage in decisions and manage their health in an informed and effective way [48].

According to the results of the present study, two chronic diseases including hypertension and diabetes mellitus are the main cause of CKD in more than half of patients (59.3\%). The literature review also reveals that these two diseases are the most important cause of CKD, which supports the results of the present study [51, 52].

The results showed no statistically significant difference in the mean SDM-Q-9 score based on sex, occupation, and place of residence. However, other variables such as patients' education level, income, and age had a significant effect on the mean SDM-Q-9 score. According to the results, patients with higher education had a high SDM score. It seems that those with more education have more information about their disease and therefore try to participate consciously in care and clinical decisions. Therefore, they are more likely to take advantage of SDM. In line with our results, a study in Washington by Seo et al. [53] showed that people with higher health literacy levels were generally 2 times more likely to participate in treatment decisions than people with lower literacy levels. Mostafaie et al. also showed that people with higher education levels are more inclined to make shared decisions [54]. These results support the findings of our study.

The results of the present study also indicate that people's income level also affects decision-making, so that people with higher income had more participation in clinical decisions. We could find no relevant study in this regard.

The results of the current study also showed an inverse relationship between the age and SDM-Q-9 scores so that with increasing age, the SDM score decreases. In this regard, Finderup et al. [49] found that although international guidelines recommend that patients should be involved in SDM, this is not always possible and older patients older than 65 years could not involved in the SDM process or unwilling to participate in care decisions \{Finderup, $2019 \# 186$ \}.

However, the mean age of the patients participating in this study was $54.84 \pm 14.98$ years and most of them could engage in the SDM on dialysis choice. Since there are no specific programs in hemodialysis units (including these two dialysis centers), most of the patients are not involved in SDM for the choice of dialysis.
Overall, the mean total SDM-Q-9 score among all participants (PD and HD) was $48.75 \pm 35.52$ out of the standardized score of 100. In a study carried out in Germany by Robinski et al. the mean total SDM-Q-9 score was $59.72 \pm 24.33$; which is higher than our results [43]. According to the results, the mean score of each item of SDM-Q-9 in our study is lower than two other studies carried out by Robinski et al. [43], and Finderup et al. [55]. The reason for these differences is related to the differences in the prevailing care approaches in different countries. Moreover, in developed countries such as Germany, there are dialysis staffs who work as dialysis coordinators. They play an important role in coordinating and involving the patient and their family in decisions related to choosing the dialysis. But, the person-centered care approach is not yet prevalent in our country, and most decisions are made by the medical team. Ambigapathy et al. believe that no patient decision should be made without patient involvement in health care systems [56].

Lee et al. reported that approximately 29\% of CKD people did not complete the SDM process. They believed that this could be attributed to a lack of information on SDM, poor family support, and inappropriate initiation of SDM by the medical team. The ideal time to start SDM for RRT involves the early stage of CKD or initiation of stage V CKD, which can prevent the onset of emergency dialysis in hospitals, which is often carried out using a temporary hemodialysis catheter. The results of a recent study showed that the implementation of SDM increases the selection of PD and kidney transplantation rather than hemodialysis [57].

The results of the present study showed a statistically significant difference between PD and HD patients in terms of the mean SDM-Q-9 score; the mean SDM score in PD patients $(73.52 \pm 24.6824)$ was higher than HD patients $(39.43 \pm 31.65)$. In a study in the United States, Zee et al. (2018) found that PD patients were more consciously involved in decision-making for the selection of the dialysis type compared to HD patients [58]. Also, in another study done by Robinski et al. [43], the results showed that PD patients had a higher SDM score $(83.80 \pm 24.42)$ than HD patients $(61.36 \pm 34.97)$, which is consistent with the findings of the present study. In Iran, there are more than 30,000 patients with HD while about 1600 patients with PD. It seems that most of the HD patients do not participate in the shared decision making process and they need more information to engage in decisions to choose one of the dialysis modality.

Finderup et al. [59] argued that factors impeding shared decision making in dialysis choice include providing biased or incomplete information on the dialysis options, not offering discussions and clarifications between 
patients and healthcare professionals, and lack of time before initiating dialysis. Thus, the choice between the choices of dialysis modalities should be selected based on patient preferences, and patients and their families should be encouraged to engage in the dialysis modality decision [58].

Based on the literature review, the choice of dialysis type varies depending on the preference and the lifestyle of each patient. In this regard, international guidelines recommend patients with CKD to involve in the SDM on dialysis modality selection based on the patient's preferences and abilities $[55,60]$. In some contexts, a physician or treatment staff have made decisions regarding HD and PD based on the patient's clinical conditions, regardless of the patient's preference and abilities $[28,61]$. Similarly, in a study conducted in Germany in 2016, more than one-fourth of the HD patient stated that dialysis modality selection was made by a nephrologist without asking for their decisions and opinions [43]. A systematic review study showed that out of 18 studies, in 10 studies, patients and their families believed that they did not receive sufficient SDM-related information [62]. In a study in the United Kingdom, Durand et al. [63] found that more than half of patients with chronic kidney disease were unaware of all RRTs as a potential treatment and were reluctant to talk with their healthcare professionals about it. Balzer et al. also emphasize the importance of awareness of patients with ESKD and their relatives about dialysis methods to strengthen the patient's empowerment and selection of home based dialysis. This study also reveals that PD patients, compared to HD patients, were more informed about the different methods before the initiation of dialysis and stated that they were provided with sufficient information [64].

This study has some limitations. This is the crosssectional study which conducted in two educational hospitals, and it should be cautious when generalizing the results of this study to other dialysis centers. Moreover, we studied the SDM from the perspective of patients. Therefore, a larger multicenter study which includes the experience of healthcare professionals, patients, and their family on shared decision making in selecting a dialysis modality choice could provide further insight in this regard.

\section{Conclusion}

Overall, the results of the present study showed a low and non-optimal SDM score in choosing the type of dialysis as compared to other studies. However, PD patients showed a better situation than HD patients and the SDM-Q-9 score was higher among PD patients compared with HD patients. Therefore, it is recommended to provide patients (especially HD patients) and their families with sufficient information on the type of RRT.
Moreover, the health care team should involve patients and their families in dialysis-related decisions in a stepby-step manner. Implementing shared decision making and providing information on RRT should be started in the early stage of CKD. Moreover, it would be helpful to use a dialysis coordinator to improve the relationship between the patient and the medical team regarding the selection of dialysis modality. Another opportunity is to allow patients to have a plan of transitions and possible scenarios for transitions from one dialysis modality to another modality bases on the patients' preference or clinical outcomes. Both patients and clinicians should follow this new paradigm of treatment that is to include the management of transitions between modalities toward better outcomes and survival in the career of CKD. The better approach should be to propose home dialysis whenever possible based on clinical and health economy sustainability.

The findings regarding shared decision making should be incorporated into the care of patients with CKD. The health care providers should involve patients with CKD and their families in dialysis-related decisions and this should be started in the early stage of CKD. Selecting a dialysis coordinator could improve the relationship between the patient and the medical team regarding the selection of dialysis modality.

\section{Acknowledgements}

This research is related to the MSc thesis project of first author in the Tabriz University of Medical Sciences. We thank all patients who participated in this study.

\section{Authors' contributions}

SG, MG, AG participated in study conception and design. SG collected the data. Data analysis and drafting of the article were done by SG, MG, AG. All authors reviewed the manuscript. The authors read and approved the final manuscript

\section{Funding}

Tabriz University of medical sciences provided the financial support (code: 1398.1009).

\section{Availability of data and materials}

The datasets used and/or analyzed during the current study available from the corresponding author on reasonable request.

\section{Ethics approval and consent to participate}

The present study has been approved by the Regional Committee of Medical Ethics of Tabriz University of Medical Sciences (Ethical code: IR.TBZMED.REC.1398.1009). The objectives of the study were provided to all participants and written informed consent was obtained from all subjects or from a parent and/or the legal guardian.

Consent for publication

Not Applicable.

Competing interests

There are no conflicts of interest. 
Received: 28 November 2020 Accepted: 15 February 2021 Published online: 23 February 2021

\section{References}

1. Venuthurupalli SK, Hoy WE, Healy HG, Cameron A, Fassett RG. CKD.QLD: establishment of a chronic kidney disease [CKD] registry in Queensland, Australia. BMC Nephrol. 2017;18(1):189.

2. Levey AS, Becker C, Inker LA. Glomerular filtration rate and albuminuria for detection and staging of acute and chronic kidney disease in adults: a systematic review. Jama. 2015;313(8):837-46.

3. Jager KJ, Fraser SDS. The ascending rank of chronic kidney disease in the global burden of disease study. Nephrol Dial Transplant. 2017;32(suppl_2):ii121-8.

4. Hamidi M, Roshangar F, Khosroshahi HT, Hadi H, Ghafourifard M, Sarbakhsh P. Comparison of the effect of linear and step-wise sodium and ultrafiltration profiling on dialysis adequacy in patients undergoing hemodialysis. Saudi J Kidney Dis Transplant. 2020;31(1):44-52.

5. Morton RL, Schlackow I, Mihaylova B, Staplin ND, Gray A, Cass A. The impact of social disadvantage in moderate-to-severe chronic kidney disease: an equity-focused systematic review. Nephrol Dial Transplant. 2016;31(1):46-56.

6. Jha V, Garcia-Garcia G, Iseki K, Li Z, Naicker S, Plattner B, Saran R, Wang AY, Yang CW. Chronic kidney disease: global dimension and perspectives. Lancet. 2013;382(9888):260-72.

7. Liyanage T, Ninomiya T, Jha V, Neal B, Patrice HM, Okpechi I, Zhao MH, LV J, Garg AX, Knight J, et al. Worldwide access to treatment for end-stage kidney disease: a systematic review. Lancet. 2015;385(9981):1975-82.

8. Axelrod DA, Schnitzler MA, Xiao H, Irish W, Tuttle-Newhall E, Chang S-H, Kasiske $\mathrm{BL}$, Alhamad T, Lentine KL. An economic assessment of contemporary kidney transplant practice. Am J Transplant. 2018;18(5):1168-76.

9. Bikbov B, Purcell CA, Levey AS, Smith M, Abdoli A, Abebe M, Adebayo OM, Afarideh M, Agarwal SK, Agudelo-Botero M, et al. Global, regional, and national burden of chronic kidney disease, 1990-2017: a systematic analysis for the global burden of disease study 2017. Lancet. 2020;395(10225):709-33.

10. Ghafourifard M, Rafieian M, Shahgholian N, Mortazavi M. Impact of two types of sodium and ultra filtration profiles on systolic and diastolic blood pressure in patients during hemodialysis. Hayat. 2010;16(1):5-12.

11. Heidary Rouchi A, Mansournia MA, Aghighi M, Mahdavi-Mazdeh M. Survival probabilities of end stage renal disease patients on renal replacement therapy in Iran. Nephrology. 2018;23(4):331-7.

12. Shahgholian N, Ghafourifard M, Shafiei F. The effect of sodium and ultra filtration profile combination and cold dialysate on hypotension during hemodialysis and its symptoms. Iran J Nurs Midwifery Res. 2011;16(3):212.

13. Saran R, Robinson B, Abbott KC, Agodoa LY, Albertus P, Ayanian J, Balkrishnan R, Bragg-Gresham J, Cao J, Chen JL, et al. US renal data system 2016 annual data report: epidemiology of kidney disease in the United States. Am J Kidney Dis. 2017;69(3 Suppl 1):A7-a8.

14. Shahgholian N, Ghafourifard M, Rafieian M, Mortazavi M. Impact of two types of sodium and ultra filtration profiles on Intradialytic hypotension in hemodialysis patients. Iran J Nurs Midwifery Res. 2008;13(4):135-9.

15. Dialysis concercium in Iran [http://www.icdgroup.org/Content/Upload/pdf/ salnama95.pdf].

16. Farah SS, Alhaji MM, Ahmed D, Alam S, Johan NH, Zulkipli IN, Khalil MA, Tan J. Barriers to kidney transplantation as a choice of renal replacement therapy. Transplant Proc. 2018;50(10):3165-71.

17. Cassidy BP, Harwood L, Getchell LE, Smith M, Sibbald SL, Moist LM. Educational support around Dialysis modality decision making in patients with chronic kidney disease: qualitative study. Can J Kidney Health Dis. 2018;5:2054358118803323.

18. Ghafourifard M, Rafieian M, Shahgholian N, Mortazavi M. Effect of sodium dialysate variation in combining with ultra filtration on intradialytic hypotension and intradialytic weight gain for patients on hemodialysis. J Mazandaran Univ Med Sci. 2009:19(72):19-26.

19. Hoffmann TC, Légaré F, Simmons MB, McNamara K, McCaffery K, Trevena $L$, Hudson B, Glasziou PP, Del Mar CB. Shared decision making: what do clinicians need to know and why should they bother? Med J Aust. 2014; 201(1):35-9.

20. Davison SN, Levin A, Moss AH, Jha V, Brown EA, Brennan F, Murtagh FE, Naicker S, Germain MJ, O'Donoghue DJ, et al. Executive summary of the KDIGO controversies conference on supportive Care in Chronic Kidney Disease: developing a roadmap to improving quality care. Kidney Int. 2015; 88(3):447-59.
21. Glatzer M, Panje CM, Sirén C, Cihoric N, Putora PM. Decision making criteria in oncology. Oncology. 2020;98(6):370-8.

22. Zhang J, Marmor R, Huh J. Towards supporting patient decision-making in online diabetes communities. AMIA Annu Symp Proc. 2017;2017:1893-902.

23. Ahmadpour B, Ghafourifard M, Ghahramanian A. Trust towards nurses who care for haemodialysis patients: a cross-sectional study. Scand J Caring Sci. 2020;34(4):1010-6

24. Tennankore KK, Hingwala J, Watson D, Bargman JM, Chan CT. Attitudes and perceptions of nephrology nurses towards dialysis modality selection: a survey study. BMC Nephrol. 2013;14(1):1-6.

25. Chan CT, Blankestijn PJ, Dember LM, Gallieni M, Harris DCH, Lok CE, Mehrotra R, Stevens PE, Wang AY-M, Cheung M, et al. Dialysis initiation, modality choice, access, and prescription: conclusions from a kidney disease: improving global outcomes (KDIGO) controversies conference. Kidney Int. 2019;96(1):37-47.

26. Finderup J, Jensen JD, Lomborg K. Shared decision-making in dialysis choice has potential to improve self-management in people with kidney disease: a qualitative follow-up study. J Adv Nurs. 2020.

27. Tsang JY, Blakeman T, Hegarty J, Humphreys J, Harvey G. Understanding the implementation of interventions to improve the management of chronic kidney disease in primary care: a rapid realist review. Implement Sci. 2016;11:47.

28. Song MK, Lin FC, Gilet CA, Arnold RM, Bridgman JC, Ward SE. Patient perspectives on informed decision-making surrounding dialysis initiation. Nephrol Dial Transplant. 2013;28(11):2815-23.

29. Winterbottom A, Bekker HL, Conner M, Mooney A. Choosing dialysis modality: decision making in a chronic illness context. Health Expect. 2014; 17(5):710-23.

30. Dahlerus C, Quinn M, Messersmith E, Lachance L, Subramanian L, Perry E, Cole J, Zhao J, Lee C, McCall M, et al. Patient perspectives on the choice of Dialysis modality: results from the empowering patients on choices for renal replacement therapy (EPOCH-RRT) study. Am J Kidney Dis. 2016;68(6):901-10.

31. Rahimi SA, Alizadeh M, Légaré F. Shared decision making in Iran: current and future trends. Z Evid Fortbild Qual Gesundheitswes. 2017;123-124:52-5.

32. Pike $E$, Hamidi $V$, Ringerike T, Wisloff $T$, Klemp M. More use of peritoneal Dialysis gives significant savings: a systematic review and health economic decision model. J Clin Med Res. 2017;9(2):104-16.

33. Aghajanloo A, Ghafourifard M, Haririan H, Shiri Gheydari P. Comparison of the effects of cryotherapy and placebo on reducing the pain of arteriovenous fistula cannulation among hemodialysis patients: a randomized control trial. JNMS. 2016;3(1):59-65.

34. Erlang AS, Nielsen $\mathrm{IH}$, Hansen HO, Finderup J. Patients experiences of involvement in choice of dialysis mode. J Ren Care. 2015;41(4):260-7.

35. Juergensen $E$, Wuerth $D$, Finkelstein $\mathrm{SH}$, Juergensen PH, Bekui A, Finkelstein FO. Hemodialysis and peritoneal dialysis: patients' assessment of their satisfaction with therapy and the impact of the therapy on their lives. Clin J Am Soc Nephrol. 2006;1(6):1191-6.

36. Gillespie BW, Morgenstern H, Hedgeman E, Tilea A, Scholz N, Shearon T, Burrows NR, Shahinian VB, Yee J, Plantinga L, et al. Nephrology care prior to end-stage renal disease and outcomes among new ESRD patients in the USA. Clin Kidney J. 2015;8(6):772-80.

37. Yeates $\mathrm{K}$, Zhu N, Vonesh $\mathrm{E}$, Trpeski L, Blake P, Fenton S. Hemodialysis and peritoneal dialysis are associated with similar outcomes for end-stage renal disease treatment in Canada. Nephrol Dial Transplant. 2012;27(9):3568-75.

38. Kim HJ, Park J, Han SH, Yoo TH, Park HC, Kang SW, Kim KH, Ryu DR, Kim H. The pattern of choosing dialysis modality and related mortality outcomes in Korea: a national population-based study. Korean J Intern Med. 2017;32(4):699-710.

39. Saran R, Robinson B, Abbott KC, Agodoa LYC, Bhave N, Bragg-Gresham J, Balkrishnan R, Dietrich X, Eckard A, Eggers PW, et al. US renal data system 2017 annual data report: epidemiology of kidney disease in the United States. Am J Kidney Dis. 2018;71(3 Suppl 1):A7.

40. Wasserfallen JB, Moinat M, Halabi G, Saudan P, Perneger T, Feldman HI, Martin PY, Wauters JP. Satisfaction of patients on chronic haemodialysis and peritoneal dialysis. Swiss Med Wkly. 2006;136(13-14):210-7.

41. Gonçalves FA, Dalosso IF, Borba JM, Bucaneve J, Valerio NM, Okamoto CT, Bucharles SG. Quality of life in chronic renal patients on hemodialysis or peritoneal dialysis: a comparative study in a referral service of Curitiba - PR. J Bras Nefrol. 2015:37(4):467-74.

42. Kao TW, Chang YY, Chen PC, Hsu CC, Chang YK, Chang YH, Lee LJ, Wu KD, Tsai TJ, Wang JD. Lifetime costs for peritoneal dialysis and hemodialysis in patients in Taiwan. Perit Dial Int. 2013;33(6):671-8. 
43. Robinski M, Mau W, Wienke A, Girndt M. Shared decision-making in chronic kidney disease: a retrospection of recently initiated dialysis patients in Germany. Patient Educ Couns. 2016;99(4):562-70.

44. Harwood L, Clark AM. Understanding pre-dialysis modality decision-making: a meta-synthesis of qualitative studies. Int J Nurs Stud. 2013;50(1):109-20.

45. Ladin K, Lin N, Hahn E, Zhang G, Koch-Weser S, Weiner DE. Engagement in decision-making and patient satisfaction: a qualitative study of older patients' perceptions of dialysis initiation and modality decisions. Nephrol Dial Transplant. 2017;32(8):1394-401.

46. Santema TB, Stubenrouch FE, Koelemay MJ, Vahl AC, Vermeulen CF, Visser MJ, Ubbink DT. Shared decision making in vascular surgery: an exploratory study. Eur J Vasc Endovasc Surg. 2016;51(4):587-93.

47. Vahdat S, Hamzehgardeshi L, Hessam S, Hamzehgardeshi Z. Patient involvement in health care decision making: a review. Iran Red Crescent Med J. 2014:16(1):e12454

48. Vélez-Bermúdez M, Christensen AJ, Kinner EM, Roche Al, Fraer M. Exploring the relationship between patient activation, treatment satisfaction, and decisional conflict in patients approaching end-stage renal disease. Ann Behav Med. 2019;53(9):816-26.

49. Cassidy BP, Getchell LE, Harwood L, Hemmett J, Moist LM. Barriers to education and shared decision making in the chronic kidney disease population: a narrative review. Can J Kidney Health Dis. 2018:5:2054358118803322.

50. Blake PG, Brown EA. Person-centered peritoneal dialysis prescription and the role of shared decision-making. Perit Dial Int. 2020;40(3):302-9.

51. Cockwell P, Fisher LA. The global burden of chronic kidney disease. Lancet. 2020:395(10225):662-4.

52. Romagnani P, Remuzzi G, Glassock R, Levin A, Jager K, Tonelli M, Massy Z, Wanner C, Anders HJ. Chronic kidney disease. Nat Rev Dis Primers. 2017;3:17088.

53. Seo J, Goodman MS, Politi M, Blanchard M, Kaphingst KA. Effect of health literacy on decision-making preferences among medically underserved patients. Med Decis Mak. 2016;36(4):550-6.

54. Mostafaie H, Parnianfard N, Ghojazadeh M, Pourmalek A, Madanlou K, Abbaspour M, Pashazadeh F, Hajebrahimi S, Hajebrahimi A. Shared decisionmaking and its correlation with demographic characteristics of Iranian patients. Br J Medi Med Res. 2014:4:3140-7.

55. Finderup J, Dam Jensen J, Lomborg K. Evaluation of a shared decisionmaking intervention for dialysis choice at four Danish hospitals: a qualitative study of patient perspective. BMJ Open. 2019;9(10):e029090.

56. Ambigapathy $\mathrm{R}$, Chia YC. Patient involvement in decision-making: a crosssectional study in a Malaysian primary care clinic. 2016;6(1):e010063.

57. Lee C-T, Cheng C-Y, Yu T-M, Chung M-C, Hsiao C-C, Chen C-H, Wu M-J. Shared decision making increases living kidney transplantation and peritoneal Dialysis. Transplant Proc. 2019;51(5):1321-4.

58. Zee J, Zhao J, Subramanian L, Perry E, Bryant N, McCall M, Restovic Y, Torres $\mathrm{D}$, Robinson BM, Pisoni RL, et al. Perceptions about the dialysis modality decision process among peritoneal dialysis and in-center hemodialysis patients. BMC Nephrol. 2018;19(1):298.

59. Finderup J, Lomborg K, Jensen JD, Stacey D. Choice of dialysis modality: patients' experiences and quality of decision after shared decision-making. BMC Nephrol. 2020;21(1):1-12.

60. Wong B, Ravani P, Oliver M, Holroyd-Leduc J, Venturato L, Garg AX, Quinn RR. Comparison of patient sunvival between hemodialysis and peritoneal Dialysis among patients eligible for both modalities. Am J Kidney Dis. 2018;71(3):344-51.

61. Johansson L. Shared decision making and patient involvement in choosing home therapies. J Ren Care. 2013;39(Suppl 1):9-15.

62. Morton R. Do Dialysis decision aids improve treatment decision-making? Perit Dial Int. 2016;36(4):359-61.

63. Durand MA, Bekker HL, Casula A, Elias R, Ferraro A, Lloyd A, van der Veer SN, Metcalfe W, Mooney A, Thomson RG, et al. Can we routinely measure patient involvement in treatment decision-making in chronic kidney care? A service evaluation in 27 renal units in the UK. Clin Kidney J. 2016:9(2):252-9.

64. Balzer MS, Clajus C, Eden G, Euteneuer F, Haller HG, Martin H, Patecki M, Schmitt R, Hiss M, Fuerholzer K. Patient perspectives on renal replacement therapy modality choice: a multicenter questionnaire study on bioethical dimensions. Perit Dial Int. 2019;39(6):519-26.

\section{Publisher's Note}

Springer Nature remains neutral with regard to jurisdictional claims in published maps and institutional affiliations.

\section{Ready to submit your research? Choose BMC and benefit from:}

- fast, convenient online submission

- thorough peer review by experienced researchers in your field

- rapid publication on acceptance

- support for research data, including large and complex data types

- gold Open Access which fosters wider collaboration and increased citations

- maximum visibility for your research: over $100 \mathrm{M}$ website views per year

At $\mathrm{BMC}$, research is always in progress.

Learn more biomedcentral.com/submissions 